\title{
Factors associated with general well-being among Lebanese adults: The role of emotional intelligence, fear of COVID, healthy lifestyle, coping strategies (avoidance and approach)
}

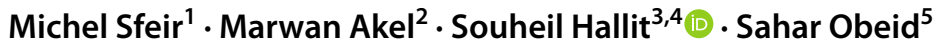 \\ Accepted: 17 November 2021 \\ @ The Author(s), under exclusive licence to Springer Science+Business Media, LLC, part of Springer Nature 2021
}

\begin{abstract}
General well-being is best described as the state of mind that gives people happiness and satisfaction in life. This concept is influenced by behaviors and attitudes that individuals do on a daily basis. The purpose of this study was to understand how general well-being is correlated with other factors such as emotional intelligence, Covid-19-induced fear, healthy lifestyle, and coping strategies. This cross-sectional study was carried out between December 2020 and January 2021 during the COVID19 pandemic when lockdown restrictions were implemented at different instances. A total of 470 individuals participated. The results of a linear regression, taking the general well-being schedule score as the dependent variable, showed that more avoidance coping $(B=1.05, t(459)=8.44, p<0.001)$, higher healthy lifestyle scores $(B=0.45, t(459)=5.45, p<0.001)$, and more approach coping $(B=0.42, t(459)=4.03, p<0.001)$ were significantly associated with higher $\mathrm{GWB}$ schedule scores. Moreover, having more fear of COVID-19 $(\mathrm{B}=-0.62, \mathrm{t}(459)=-5.09, \mathrm{p}<0.001)$ and female gender $(\mathrm{B}=-6.80, \mathrm{t}(459)=-4.34$, $\mathrm{p}<0.001)$ were significantly associated with lower GWB schedule scores. To our knowledge, this is the first study in Lebanon to evaluate GWB and factors that predict it among the general population. Nevertheless, more comprehensive future studies with longitudinal designs, more diverse socio-demographic backgrounds of sampled population recruited via probability sampling, and more reliable and valid instruments utilized are warranted to confirm our findings and draw a more certain conclusion.
\end{abstract}

Keywords General well-being $\cdot$ Emotional intelligence $\cdot$ COVID- $19 \cdot$ Healthy lifestyle $\cdot$ Coping strategies

\section{Abbreviations \\ GWB General Well-being \\ EI emotional intelligence}

Souheil Hallit and Sahar Obeid are last co-authors.

Souheil Hallit

souheilhallit@hotmail.com

Sahar Obeid

saharobeid23@hotmail.com

$1 \quad$ Institute of Psychology (IP), Faculty of social and political sciences, University of Lausanne, Lausanne, Switzerland

2 School of Pharmacy, Lebanese International University, Beirut, Lebanon

3 Faculty of Medicine and Medical Sciences, Holy Spirit University of Kaslik (USEK), Jounieh, Lebanon

4 Research Department, Psychiatric Hospital of the Cross, Jal Eddib, Lebanon

5 Faculty of Arts and Sciences, Holy Spirit University of Kaslik (USEK), Jounieh, Lebanon
PA Physical activity

WHO World Health Organization

HLST Healthy Lifestyle Screening Tool

FCVS-19 Fear of COVID-19 Scale

SSEIT Schutte Self-report Emotional Intelligence

Test

SPSS Statistical package for the Social Sciences

\section{Introduction}

The concept of General Well-being (GWB) dates back to the time of ancient Greece where one of the main purposes of philosophers back then was how to acquire the good life or what we now know as well-being (Stoll, 2014). Later on, the concept of wellbeing was separated from the "good life" as soon as it started to be considered as a scientific topic that can be measured and studied. The measurement of wellbeing would be the basic substance that is "pleasure" (Stoll, 2014). Different ideas on how 
to create a "good life" were proposed such as equality and autonomy in order to create a utopian environment or society (Levinson \& Christensen, 2003; Stoll, 2014). Moreover, the concept of wellbeing was explained by John Locke $(1632-1704)$ at the end of the nineteenth century as the satisfaction of an unease that both women and men have naturally - and that humans can be satisfied in different ways; "we cannot unify one version of satisfaction as numerous things make many people happy. That's why the focus was on the internal comfort which is subjective, rather than the external one" (Stoll, 2014).

The state of well-being or happiness can be influenced by some factors such as emotional intelligence or comprehension that might interplay with this process (GuerraBustamante et al., 2019). Our purpose in this study is to understand the correlation between this state of wellbeing, as defined above, and various other factors...

As mentioned earlier, one of the factors that is correlated with the wellbeing of individuals is emotional intelligence (EI) (Di Fabio \& Kenny, 2016). EI is the ability to understand and regulate one's emotions or those of their surroundings in order to achieve growth on emotional and intellectual levels (Salovey \& Sluyter, 1997). In other words, EI can be seen as how people process and experience emotions and information (Hodzic et al., 2018). In previous studies, lower EI was associated with more mental health problems (Obeid et al., 2019a; Obeid et al., 2021; Obeid et al., 2020b; Obeid et al., 2020a) and work fatigue (Lahoud et al., 2019), whereas higher EI was correlated with higher self-esteem (Obeid et al., 2019b), happiness and well-being (Cejudo et al., 2018). A metaanalysis showed that EI has an influence on subjective well-being. Hence, the use of coping, emotional strategies can be correlated with an increase of positive emotions and a decrease of unwanted emotions that may cause a state of distress, therefore influencing the well-being of individuals (Sánchez-Álvarez et al., 2016).

Another factor is the healthy lifestyle; in 1972, the Alameda County Study described 7 healthy lifestyle habits: practicing physical activity, not smoking, drinking alcohol moderately, having an average weight, sleeping between 7 and $8 \mathrm{~h}$, having breakfast, and not eating between the meals; these 7 healthy practices were said to be related to better well-being and a healthier lifestyle (Belloc \& Breslow, 1972). Furthermore, in a study conducted in 2020, people who partook in physical activities had balanced diets and good sleep patterns which are two elements associated with better mental health during the COVID-19 pandemic (Kilani et al., 2020). Physical activity (PA) was associated with better health and a lower risk of mortality and chronic illnesses (Warburton \& Bredin, 2016). Thus, regular PA can be associated with higher level of well-being compared to low PA (Harris, 2018).
Engaging in PA was correlated with a healthy mental and physical state (Fromel et al., 2017). As a result, having a healthy lifestyle would be correlated with greater life satisfaction, which would generate the feeling of GWB (Martin-Maria et al., 2020).

According to the World Health Organization (WHO), almost $60 \%$ of the factors related to quality of life and individual health are associated with lifestyle (World Health Organization, 2004). PA and physical health are enhanced by EI. Individuals with high EI are more motivated to practice PA (Lane et al., 2010; Pulido-Martos et al., 2014). High levels of EI were shown to be correlated with a positive affect while practicing; therefore, increasing the individual's level of happiness and the state of tranquility and decreasing his/ her levels of fatigue, anger and depression (Lane et al., 2010; Lane \& Wilson, 2011; Pulido-Martos et al., 2014).

The fear of COVID-19 that was associated with some mental disturbances such as depression and anxiety influenced individuals' GWB according to numerous studies (Ahorsu et al., 2020; Chen et al., 2020; Mertens et al., 2020). This pandemic was considered a stressor in all countries and affects mental health (El Othman et al., 2021a; Xiong et al., 2020). The results of a study showed that the fear of COVID-19 and the intolerance of uncertainty affected the community's well-being because of the constant focus on negative emotions (Satici et al., 2020). In a study conducted on Saudi adults, the COVID-19 pandemic was correlated with high levels of anxiety and fear, and this fear of COVID19 was also correlated with a lower GWB (Alyami et al., 2021). Another study found that the fear of COVID-19 was related to the intolerance of uncertainty by the presence of rumination and the focus on negative effect, which would also affect the GWB (Satici et al., 2020).

GWB also depends on how people react to situations or what coping strategies they employ. Coping strategies help individuals handle internal and external stressors (MarquezArrico et al., 2015). Two common coping strategies are known as avoidance coping and approach coping. Avoidance coping is defined as avoiding stressful events and not wanting to face them; whereas approach one is about facing the situation (Fauerbach et al., 2009). An avoidance strategy might be associated with a decrease in well-being (Arble $\&$ Arnetz, 2017). However, having a positive coping style would mean to face the situation even if it is stressful and try to overcome it or modify it either by using problem-solving techniques or seeking help (Doron et al., 2013; Kotze et al., 2013). This method specifically would eventually enhance the GWB of individuals (Gustems-Carnicer \& Calderón, 2013).

Factors affecting the GWB can interplay with one another. Emotional intelligence can be explained as the individual's ability to understand his emotions and better perceive or interpret situations that he or she encounters 
(Sánchez-Álvarez et al., 2016). This is why emotional intelligence can be correlated with the fear of COVID-19 as EI could influence how someone would cope with the fear or the anxiety that occurred due to the COVID-19 pandemic. The ability to understand or interpret the situation would eventually affect an individual's GWB (Moron \& BiolikMoron, 2021). Emotional capacities help people cope with everyday stressors and improve their positive attitude regarding life problems and events which, in turn, would lead to a better feeling of GWB, hence the importance of the EI to improving the coping strategies (Schutte et al., 2007). Risk factors for anxiety, distress and depression were associated with avoidant coping (Arble \& Arnetz, 2017) and higher adaptation and control in approach coping, hence the impact on the GWB (Juth et al., 2015). Moreover, better diet, sleep and PA were correlated with less stress and anxiety, which means an increase of the GWB. The healthy lifestyle can influence and be influenced by the fear of COVID-19 (Kilani et al., 2020). The fear of COVID-19 and the exposure to the coronavirus were also associated with a higher level of fear and worry (Garfin et al., 2020). The proposed association between the GWB, emotional intelligence, fear of COVID19 , coping strategies and healthy lifestyle is illustrated in Fig. 1.

In light of the current pandemic and the economic crisis in Lebanon and their high correlation with anxiety and stress (El Othman et al., 2021a; Salameh et al., 2020), it seems necessary to evaluate the GWB of the Lebanese population. The mental health of the Lebanese citizens was strongly affected by the political and economic instability happening lately (Rayan \& Fawaz, 2018), and the pandemic itself (El Othman et al., 2021a, 2021b). Therefore, due to the lack of sufficient data about factors affecting well-being, this research paper aimed to study the association of some factors such as emotional intelligence, healthy lifestyle, fear of COVID-19 and coping strategies with the GWB of people. In our study, we hypothesized that low emotional intelligence, higher fear of COVID-19, low healthy lifestyle and more avoidance coping strategy would be associated with lower GWB.

\section{Methods}

\section{Study Design}

This cross-sectional study was carried out between December 2020 and January 2021, during the COVID-19 pandemic when lockdown restrictions were implemented at different instances, and the measures taken by the government were changing on regular basis according to the severity of the COVID-19 situation. In response to this situation, the data collection was performed through an online questionnaire. This was made possible using Google Forms, a free to use software available to anyone with internet access. The sample was selected from five Lebanese districts (Beirut, Bekaa, Mount Lebanon, South Lebanon and North Lebanon) using a snowball technique. The recruitment of participants started by word of mouth and then, the first participants aided in the recruitment of other participants (recruiting participants as diverse as possible in regards of place of residence within the Lebanese governorates), until the total amount of people need to complete the sample was reached. The link was shared with all the participants via the WhatsApp application who were briefed about the topic, and the different aspects of the questionnaire before filling it out, while being assured of the anonymity of their responses. The selection criteria included people aged 18 years and above and excluded those who refused to participate in the study.

Two clinical psychologists performed the forward and back translations (from English to Arabic and from Arabic to
Fig. 1 Conceptual Framework of the Association between Emotional intelligence, Coping Strategies, Healthy Lifestyle, Fear of COVID-19 and General Well-being (Garfin et al., 2020; Juth et al., 2015; Kilani et al., 2020; Moron \& Biolik-Moron, 2021)

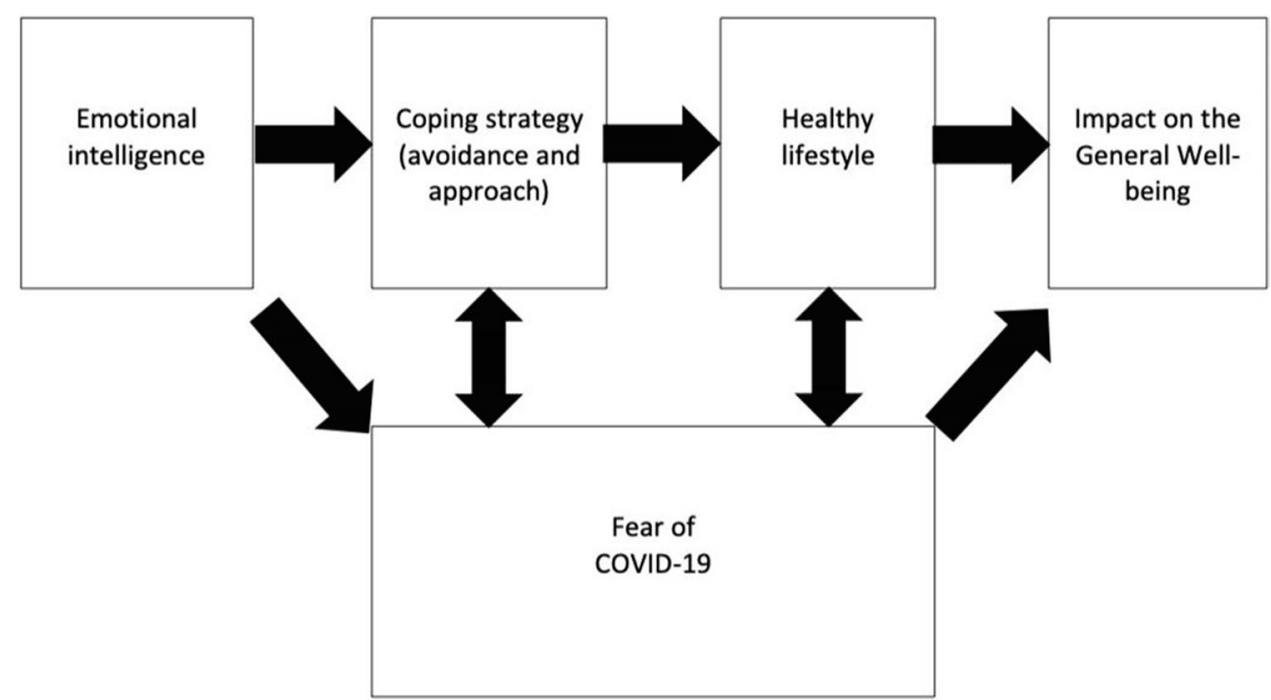


English) for all scales. The principal investigator compared the back-translated English questionnaire with the original English questionnaire to detect inconsistencies and solve discrepancies between the two versions. A pilot study was done on 15 people to ensure face validity of the translated version of the questionnaire. Minor corrections were resolved by consensus between the three parties.

\section{Minimal Sample Size Calculation}

According to the G-power software, and based on an effect size $\mathrm{f}^{2}=2 \%$, an alpha error of $5 \%$, a power of $80 \%$, and taking into consideration 10 factors to be entered in the multivariable analysis, the results showed that a minimal number of 395 participants was needed.

\section{Questionnaire}

The questionnaire sent to participants was in Arabic, the native language in Lebanon. It required an estimated 20 to 25 min to be completed and was composed of two parts. The first part tackled the sociodemographic data and the second one involved targeting the variables being evaluated.

\section{Sociodemographic Data}

In this part of the questionnaire, participants were asked about their general sociodemographic data, including age, educational level, income, marital status, number of children and member of residents in the household. The latter was calculated by dividing the number of people living in the house by the number of rooms (excluding Kitchen and bathroom) (Melki et al., 2004).

\section{Scale-Based Category}

The following scales were used in the questionnaire:

The General Well-Being Schedule (GWBS) The GWBS is a self-administered tool including questions that put the emphasis on the person's subjective feelings of psychological well-being and distress. There are 18 items in this questionnaire that cover 6 dimensions of anxiety, depression, general health, positive well-being, self-control and vitality. From question 1 till 14, there are 6 response scales, each one representing the intensity or the frequency, and the four other questions use 0 to 10 rating scales (Dupuy et al., 1977).

Healthy Lifestyle Screening Tool (HLST) The HLST consists of 36 items that measure 9 factors (i.e., 4 items per factor). The 9 factors, each of which consists of 4 items, are as follows: sunlight (items 1 to 4 ), water (items 5 to 8), air (items 9 to 12 ), rest (items 13 to 16 ), exercise (items 17 to 20), nutrition (items 21 to 24), temperance (items 25 to 28), trust (items 29 to 32), and general physical condition (items 33 to 36 ). Scores are computed using responses recorded on the following 4-point Likert rating scale: $4=$ strongly agree, $3=$ agree, $2=$ disagree, and $1=$ strongly disagree. Scores on the HLST can range from 36 to 144 . Higher scores on the HLST are indicative of a healthier lifestyle (Kim \& Kang, 2019).

Fear of COVID-19 Scale (FCVS-19) It is a unidimensional scale that assesses the fear of COVID-19. The instrument comprises seven items (e.g., "My heart races or palpitates when I think about getting coronavirus-19") which are responded to on a 5-point Likert scale from 1 (strongly disagree) to 5 (strongly agree). The scores obtained from the FCVS-19 vary between 7 and 35, with higher scores indicating greater fear of COVID-19 (Ahorsu et al., 2020).

Brief Cope The Brief-COPE (Coping Orientation to Problems Experienced) is a 28 -item self-reported questionnaire designed to measure effective and ineffective ways to cope with a stressful life event. Each question has 4 possible answers ranging from 1 to 4 , (1: I have not been doing this at all, 2: A little bit, 3: A medium amount and 4: I have been doing this a lot). It can be used to measure how someone is coping with a wide range of adversity. The scale can determine someone's primary coping styles as either Approach Coping, or Avoidant Coping (Carver, 1997).

Schutte Self-Report Emotional Intelligence Test (SSEIT) The SSEIT is a method of measuring general Emotional Intelligence (EI), which includes 33 self-report items graded using a 1 (strongly agree) to 5 (strongly disagree) Likert scale. Higher total scores reflect more EI (Schutte et al., 2002).

\section{Statistical Analysis}

Statistical package for the Social Sciences (SPSS) 25 was used for the data analysis. Cronbach's alpha values were recorded for all scales to assess internal reliability. The normality of distribution of the GWB schedule score was confirmed via a calculation of the skewness and kurtosis; values for asymmetry and kurtosis between -1 and +1 are considered acceptable in order to prove normal univariate distribution (Hair Jr et al., 2017). These assumptions were consolidated by our sample that included more than 300 participants (Mishra et al., 2019). Accordingly, the Student t-test was used to check for an association between the GWB score and dichotomous variables (i.e., gender and marital status) while the Pearson correlation test was used to correlate two continuous variables. A forward linear regression was conducted, taking the GWB score as the dependent variables; assumptions of normality and homoscedasticity were 
verified as well. Variables that showed a $\mathrm{p}<0.2$ in the bivariate analysis were entered as independent variables (Bursac et al., 2008). Significance was set at $\mathrm{p}<0.05$.

\section{Results}

The Cronbach's alpha values of the scales came out as follows: GWB schedule (0.889), healthy lifestyle (0.726), fear of COVID-19 (0.864), total coping scale (0.906), avoidant coping (0.796), approach coping (0.908) and emotional intelligence (0.948).

Sociodemographic and other characteristics of the participants are summarized in Table 1 . The mean age of the sample was 25.73 years (SD: 9.66 ), $70.6 \%$ of which were females. The mean GWB schedule score in our sample was $60.46 \pm 17.20$.

\section{Bivariate Analysis}

Higher GWB schedule scores were correlated to lower fear of COVID-19 $(\mathrm{r}(470)=-0.313, \mathrm{p}<0.001)$, older age $(\mathrm{r}(470)=0.109, \mathrm{p}=0.018)$, more avoidant coping $(r(470)=0.313, p<0.001)$, better healthy lifestyle $(\mathrm{r}(470)=0.292, \mathrm{p}<0.001)$, and higher emotional

Table 1 Sociodemographic and Other Characteristics of the Participants $(\mathrm{N}=470)$

\begin{tabular}{ll}
\hline Variable & $\mathrm{N}(\%)$ \\
\hline Gender & \\
$\quad$ Male & $138(29.4 \%)$ \\
$\quad$ Female & $332(70.6 \%)$ \\
Marital status & \\
$\quad$ Single / widowed / divorced & $361(76.8 \%)$ \\
$\quad$ Married & $109(23.2 \%)$ \\
Education level & \\
$\quad$ Secondary or less & $47(10.0 \%)$ \\
$\quad$ University & $423(90.0 \%)$ \\
Previous infection by COVID-19 & \\
$\quad$ No & $366(77.9 \%)$ \\
$\quad$ Yes & $104(22.1 \%)$ \\
& Mean \pm SD \\
Age (in years) & $25.73 \pm 9.66$ \\
Household crowding index & $1.01 \pm 0.41$ \\
Number of children & $0.66 \pm 1.30$ \\
Healthy lifestyle score & $93.49 \pm 8.90$ \\
Coping avoidance score & $23.45 \pm 6.05$ \\
Coping approach score & $31.48 \pm 7.97$ \\
Emotional intelligence score & $118.30 \pm 20.41$ \\
General well-being schedule score & $60.46 \pm 17.20$ \\
\hline
\end{tabular}

intelligence $(\mathrm{r}(470)=0.165, \mathrm{p}<0.001)($ Table 2$)$. Moreover, there was a significant effect for gender $\mathrm{t}(468)=5.76$, $\mathrm{p}<0.001$, with males having higher GWB schedule scores compared to females (Table 3 ).

\section{Multivariable Analysis}

The results of a stepwise linear regression, taking the GWB schedule score as the dependent variable, showed that more avoidant coping $(\mathrm{B}=1.05, \mathrm{t}(459)=8.44, \mathrm{p}<0.001)$, higher healthy lifestyle scores $(\mathrm{B}=0.45, \mathrm{t}(459)=5.45, \mathrm{p}<0.001)$, and more approach coping $(\mathrm{B}=0.42, \mathrm{t}(459)=4.03$, $\mathrm{p}<0.001)$ were significantly associated with higher GWB schedule scores. Moreover, having more fear of COVID$19(\mathrm{~B}=-0.62, \mathrm{t}(459)=-5.09, \mathrm{p}<0.001)$ and female gen$\operatorname{der}(\mathrm{B}=-6.80, \mathrm{t}(459)=-4.34, \mathrm{p}<0.001)$ were significantly associated with lower GWB schedule scores (Table 4).

Table 2 Bivariate Analysis of Continuous Variables Associated with the General Well-being Schedule Score

\begin{tabular}{lll}
\hline Variable & $\begin{array}{l}\text { Correlation coef- } \\
\text { ficient }\end{array}$ & $p$ \\
\hline Healthy lifestyle score & 0.292 & $\mathbf{< 0 . 0 0 1}$ \\
Avoidant coping score & 0.313 & $\mathbf{< 0 . 0 0 1}$ \\
Approach coping score & 0.083 & 0.074 \\
Fear of COVID-19 score & -0.313 & $\mathbf{< 0 . 0 0 1}$ \\
Emotional intelligence score & 0.165 & $\mathbf{0 . 0 0 1}$ \\
Age & 0.109 & $\mathbf{0 . 0 1 8}$ \\
Number of children & 0.052 & 0.256 \\
Household crowding index & -0.079 & 0.087 \\
\hline
\end{tabular}

Numbers in bold indicate significant p-values

Table 3 Bivariate Analysis of Categorical Variables Associated With The General Well-being Schedule Score

\begin{tabular}{llll}
\hline Variable & Mean \pm SD & $p$ & Effect size \\
\hline Gender & & $\mathbf{0 . 0 0 2}$ & 0.587 \\
$\quad$ Male & $67.31 \pm 16.22$ & & \\
$\quad$ Female & $57.61 \pm 16.81$ & & \\
Marital status & & 0.233 & 0.131 \\
$\quad$ Single / widowed / divorced & $59.94 \pm 17.33$ & & \\
$\quad$ Married & $62.18 \pm 16.71$ & & \\
Education level & & 0.087 & 0.266 \\
$\quad$ Secondary or less & $56.38 \pm 16.87$ & & \\
$\quad$ University & $60.91 \pm 17.20$ & & \\
Previous infection by COVID-19 & & 0.097 & 0.189 \\
$\quad$ No & $59.76 \pm 17.49$ & & \\
$\quad$ Yes & $62.93 \pm 15.98$ & & \\
\hline
\end{tabular}

Numbers in bold indicate significant p-values 


\section{Discussion}

This study showed a higher level of GWB associated with healthy lifestyles, avoidant and approach coping strategies whereas a lower GWB was associated with more fear of COVID-19 in females compared to males.

\section{Coping Strategies}

The results of our study revealed that more approach coping was associated with better GWB, which aligns with another study that demonstrated that an emotional approach coping was correlated with a better GWB as well as decreased stress levels (Juth et al., 2015). In this same study, individuals who had better emotional approach coping had a better cognitive and effective adaptation and had a higher feeling of being in control of their lives; this increased positive affect on their everyday lives. An approach coping strategy is linked to a higher psychological health as well as a better quality of life (Smith et al., 2002; Stanton et al., 2000).

On another hand, our study showed that higher avoidant coping was associated with higher GWB. Avoidance approach might be effective in the sense that people might take a break from the problem and distance themselves from it. Later on, they might engage in an approach coping strategy and might have more energy and motivation to work. Indeed, this distance taken may elicit a psychological space, which is important to recover from stress (Arble \& Arnetz, 2017). As the previous point was not investigated in our study, future studies are recommended to understand if those who engaged in avoidance coping would later on adopt approach coping.

\section{Fear of COVID-19}

After analysis of the data, our results showed that individuals with a higher fear of COVID-19 had significantly lower scores of well-being. Consistently with a previous research in another pandemic, such as Zika in 2015, the threat or fear of having Zika was a predictor of Zika-related anxiety (Blakey \& Abramowitz, 2017), and the same applies to the Ebola virus (Blakey et al., 2015). In fact, more media exposure to the virus would be correlated with an increase rate of fear which tends to influence the GWB of individuals; this was observed in previous pandemics such as the Ebola virus as well as the current COVID-19 pandemic (Garfin et al., 2020).

Another predictor of fear would also be the worry about the health of people surrounding the individual such as family, friends and loved ones (Mertens et al., 2020); this finding is consistent with the reports that showed that COVID-19 may cause higher harm to people at risk (elderly, people with low immune system or other health problems, etc.) (World Health Organization, 2020). In fact, the action of caregiving and taking care of a family member can be considered as a stressor that might impact GWB (Thomas et al., 2017); this aligns with the results of another study that indicated that caregivers manifested a lower mental health and reported a lower level of wellbeing compared to non-caregivers (Berglund et al., 2015). More specifically, during the COVID-19 pandemic, an impact was shown on the GWB of caregivers, which caused significantly higher levels of anxiety and depression than before the pandemic (Hughes et al., 2021).

\section{Healthy Lifestyle}

In alignment with results of previous research, a healthier lifestyle was correlated with a higher GWB (Kilani et al., 2020); the more people had better diet regimes, better sleep and more PA, the more chances of having a higher wellbeing they had (Kilani et al., 2020). For example, getting exposed to sunlight and ultraviolet radiation, can release vitamin D3 and endorphins which are both effective for the bones and health (Kilani et al., 2013; Zayed \& Kilani, 2014). In a study conducted on German and Chinese students, results showed that a healthy lifestyle has an influence on

Table 4 Multivariable Analyses: Stepwise Linear Regression Taking The General Well-being Schedule Score as the Dependent Variable

\begin{tabular}{llllllll}
\hline Variable & $\mathrm{B}$ & $\mathrm{SE}$ & $\beta$ & $\mathrm{t}$ & $p$ & $95 \%$ CI & $\begin{array}{l}\text { Added } \mathrm{R}^{2} \text { value for each } \\
\text { item being added to the } \\
\text { model }\end{array}$ \\
\hline Avoidance coping & 1.05 & 0.12 & 0.37 & 8.44 & $<0.001$ & $0.81-1.29$ & $9.6 \%$ \\
Healthy lifestyle & 0.45 & 0.08 & 0.24 & 5.45 & $<0.001$ & $0.29-0.62$ & $21.4 \%$ \\
Fear of COVID-19 & -0.62 & 0.12 & -0.20 & -5.09 & $<0.001$ & $-0.86--0.38$ & $26.9 \%$ \\
Gender (females vs males*) & -6.80 & 1.57 & -0.18 & -4.34 & $<0.001$ & $-9.88--3.72$ & $28.6 \%$ \\
Approach coping & 0.42 & 0.10 & 0.19 & 4.03 & $<0.001$ & $0.21-0.62$ & $31.0 \%$ \\
\hline
\end{tabular}

*Reference group; $\mathrm{B}=$ Unstandardized Beta; $\mathrm{SE}=$ Standard Error; $\beta=$ Standardized Beta; $\mathrm{CI}=$ Confidence Interval

Variables entered in the model: Emotional intelligence, avoidant coping, approach coping, education, gender, previous infection by COVID-19, healthy lifestyle, age, fear of COVID-19 
wellbeing. Those who engaged more in physical and mental activities, didn't smoke, and had a lower body mass index were associated with better mental health (Velten et al., 2018).

On a different note, other results showed that people who have a higher PA tend to have less stress and pain due to the secretion of hormones such as serotonin and endorphins. When these hormones are released, they give a euphoric sensation which boosts the mood and the overall well-being (Josefsson et al., 2014). In another study with adolescents, PA was associated with a decrease in anxiety and depressive symptoms (Bell et al., 2019). Individuals who engage in PA had a better general mental well-being in comparison with others who did not engage in PA (Harris, 2018).

\section{Gender}

Females were found to have lower GWB compared to males in our study, which aligns with other findings (Matud et al., 2019). The biological feature of women can be considered as another factor that might decrease their GWB (Carmel, 2019). In general, women tend to have higher worry, anxiety, stress, depression or mood changes than men; this is due to their hormonal changes and the difficulties or obstacles females might face in some societies (sexism, gender inequality, etc.) (Carmel, 2019; Carmel et al., 2018; Luppa et al., 2012). Furthermore, women who had frequent dysmenorrhea reported higher level of pain and a correlation was found between depression and premenstrual pain (Bancroft, 1995). Moreover, in another study, less severe menstrual bleeding and blood loss was correlated with an improvement in the quality of life (Lukes et al., 2012). This effect on the quality of women's lives and wellbeing comes from the menstrual bleeding and the ability to manage it, as well as the consequences of a decrease in iron and a fatigue that are caused by the blood loss (Liu et al., 2007).

\section{Clinical Implications}

The clinical implications of this study suggest that healthcare professionals should focus more on the factors that influence the GWB of individuals. By improving their emotional intelligence or providing them with more coping approach tools and techniques, they would be increasing their GWB. More organizations and associations should implement awareness sessions on what to do to avoid having low well-being and propose clinical tips to apply to everyday life to enhance GWB. A few of these tips could be as simple as integrating more PA or suggesting how to enhance emotional intelligence.

\section{Limitations}

This study evaluated the GWB among 470 Lebanese individuals; however, it does not represent the entire Lebanese population, so generalized conclusions of the characteristics of GWB among the entire population cannot be drawn. The sample in this study consisted of young adults mainly (mean age $=25.73$ years), and single $(76.8 \%)$. Although people from all Lebanese governorates were included in the sample, the sampling technique used in this study (snowball technique) limits the representativeness of our results. Furthermore, the use of an online survey limits the enrollment of people without internet access, predisposing us to a selection bias. Aside from that, the information may be biased due to some self-reported scales and/or scales that are not validated in Lebanon; hence their reliability would be questionable. Marital status might be associated with GWB and it would be interesting to evaluate it in the general Lebanese population (Gomez et al., 2019). Residual confounding bias is possible since other factors that may affect GWB and quality of life during the COVID-19 pandemic were not assessed, such as loss of daily life routine due to social distancing and movement control, the severity of depression, anxiety and stress symptoms among respondents, and the degree of social support evidence (Woon et al., 2021). Other variables that were not assessed in this study could also have an influence on GWB such as religiosity or spirituality. Previous studies assessed the correlation between religiosity and positive emotions and subjective wellbeing and found that the identity one has in religion might positively influence life satisfaction (Villani et al., 2019). Moreover, the cross-sectional type of our study does not allow causality; longitudinal studies are needed in order to assess causality between the independent variables and GWB. Despite these limitations, this study points out important factors associated to the GWB of the community during the COVID-19 pandemic.

\section{Conclusion}

We have established a positive association between a higher GWB and an approach/avoidance coping strategy, a healthier lifestyle, and in males compared to females. This may be the first study in Lebanon to evaluate GWB and its predictive factors among the general population. Nevertheless, more comprehensive future studies with a longitudinal design, a sample population with more diverse socio-demographic background recruited via probability sampling, and the use of more reliable and valid instruments are warranted to confirm our findings and draw a more certain conclusion. Furthermore, future study with mixed method design may enhance our understanding and allow researchers to envisage 
a clearer relationship between emotional intelligence, fear of COVID-19, healthy lifestyle, coping strategies, and GWB among the general population of Lebanon.

Acknowledgments The authors would like to thank all students who helped us as well as the schools' directors.

Availability of Data and Materials The authors do not have the right to share any data information as per their institutions' policies.

Authors' Contributions SO and SH conceived and designed the survey. $\mathrm{SH}$ was involved in the statistical analysis and data interpretation. MS wrote the manuscript. MA involved in the data collection and reviewed the manuscript. All authors read the manuscript, critically revised it for intellectual content, and approved the final version.

\section{Declarations}

Ethics Approval and Consent to Participate The Psychiatric Hospital of the Cross ethics committee approved the study protocol (HPC-0462020). Submitting the form online was equivalent to obtaining a written informed consent from each participant.

Consent for Publication not applicable.

Competing Interests The authors have no conflicts of interest to report.

\section{References}

Ahorsu, D. K., Lin, C. Y., Imani, V., Saffari, M., Griffiths, M. D., \& Pakpour, A. H. (2020). The fear of COVID-19 scale: Development and initial validation. International Journal of Mental Health and Addiction, 1-9. https://doi.org/10.1007/s11469-020-00270-8

Alyami, M., de Albuquerque, J. V., Krageloh, C. U., Alyami, H., \& Henning, M. A. (2021). Effects of fear of COVID-19 on mental well-being and quality of life among Saudi adults: A path analysis. Saudi Journal of Medicine and Medical Sciences, 9(1), 24-30. https://doi.org/10.4103/sjmms.sjmms_630_20

Arble, E., \& Arnetz, B. B. (2017). A model of first-responder coping: An approach/avoidance bifurcation. Stress and Health, 33(3), 223-232. https://doi.org/10.1002/smi.2692

Bancroft, J. (1995). The menstrual cycle and the well being of women. Social Science \& Medicine, 41(6), 785-791.

Bell, S. L., Audrey, S., Gunnell, D., Cooper, A., \& Campbell, R. (2019). The relationship between physical activity, mental wellbeing and symptoms of mental health disorder in adolescents: A cohort study. International Journal of Behavioral Nutrition and Physical Activity, 16(1), 138. https://doi.org/10.1186/s12966-019-0901-7

Belloc, N. B., \& Breslow, L. (1972). Relationship of physical health status and health practices. Preventive Medicine, 1(3), 409-421.

Berglund, E., Lytsy, P., \& Westerling, R. (2015). Health and wellbeing in informal caregivers and non-caregivers: A comparative cross-sectional study of the Swedish general population. Health and Quality of Life Outcomes, 13, 109. https://doi.org/10.1186/ s12955-015-0309-2

Blakey, S. M., \& Abramowitz, J. S. (2017). Psychological predictors of health anxiety in response to the Zika virus. Journal of Clinical Psychology in Medical Settings, 24(3-4), 270-278. https://doi.org/ 10.1007/s10880-017-9514-y

Blakey, S. M., Reuman, L., Jacoby, R. J., \& Abramowitz, J. S. (2015). Tracing "Fearbola": Psychological predictors of anxious responding to the threat of Ebola. Cognitive Therapy and Research, 39(6), 816-825. https://doi.org/10.1007/ s10608-015-9701-9

Bursac, Z., Gauss, C. H., Williams, D. K., \& Hosmer, D. W. (2008), Purposeful selection of variables in logistic regression. Source Code for Biology and Medicine, 3, 17. https://doi.org/10.1186/ 1751-0473-3-17

Carmel, S. (2019). Health and Well-Being in Late Life: Gender Differences Worldwide. Front Med (Lausanne), 6, 218. https://doi.org/ 10.3389/fmed.2019.00218

Carmel, S., Tovel, H., Raveis, V. H., \& O'Rourke, N. (2018). Is a decline in will to live a consequence or predictor of depression in late life? Journal of the American Geriatrics Society, 66(7), 1290-1295. https://doi.org/10.1111/jgs.15394

Carver, C. S. (1997). You want to measure coping but your protocol'too long: Consider the brief cope. International Journal of Behavioral Medicine, 4(1), 92-100.

Cejudo, J., Rodrigo-Ruiz, D., Lopez-Delgado, M. L., \& Losada, L. (2018). Emotional intelligence and its relationship with levels of social anxiety and stress in adolescents. International Journal of Environmental Research and Public Health, 15(6). https://doi.org/ 10.3390/ijerph15061073

Chen, B., Sun, J., \& Feng, Y. (2020). How have COVID-19 isolation policies affected young People's mental health? - evidence from Chinese college students. Frontiers in Psychology, 11, 1529. https://doi.org/10.3389/fpsyg.2020.01529

Di Fabio, A., \& Kenny, M. E. (2016). From decent work to decent lives: Positive self and relational management (PS\&RM) in the twenty-first century. Frontiers in Psychology, 7, 361. https://doi. org/10.3389/fpsyg.2016.00361

Doron, J., Thomas-Ollivier, V., Vachon, H., \& Fortes-Bourbousson, M. (2013). Relationships between cognitive coping, self-esteem, anxiety and depression: A cluster-analysis approach. Personality and Individual Differences, 55(5), 515-520.

Dupuy, H.J. (1977). The General Well-being Schedule. In I. McDowell \& C. Newell (Eds.), Measuring health: a guide to rating scales and questionnaire (2nd ed) (pp. 206-213). USA: Oxford University Press.

El Othman, R., Touma, E., El Othman, R., Haddad, C., Hallit, R., Obeid, S., Salameh, P., \& Hallit, S. (2021a). COVID-19 pandemic and mental health in Lebanon: A cross-sectional study. International Journal of Psychiatry in Clinical Practice, 25(2), 152-163. https://doi.org/10.1080/13651501.2021.1879159

El Othman, R., Touma, E., El Othman, R., Haddad, C., Hallit, R., Obeid, S., Salameh, P., \& Hallit, S. (2021b). COVID-19 pandemic and mental health in Lebanon: A cross-sectional study. International Journal of Psychiatry in Clinical Practice, 1-12. https:// doi.org/10.1080/13651501.2021.1879159

Fauerbach, J. A., Lawrence, J. W., Fogel, J., Richter, L., MagyarRussell, G., McKibben, J. B., \& McCann, U. (2009). Approachavoidance coping conflict in a sample of burn patients at risk for posttraumatic stress disorder. Depression and Anxiety, 26(9), 838-850. https://doi.org/10.1002/da.20439

Fromel, K., Kudlacek, M., Groffik, D., Svozil, Z., Simunek, A., \& Garbaciak, W. (2017). Promoting healthy lifestyle and well-being in adolescents through outdoor physical activity. International Journal of Environmental Research and Public Health, 14(5). https://doi.org/10.3390/ijerph14050533

Garfin, D. R., Silver, R. C., \& Holman, E. A. (2020). The novel coronavirus (COVID-2019) outbreak: Amplification of public health consequences by media exposure. Health Psychology, 39(5), 355-357. https://doi.org/10.1037/hea0000875

Gómez-López M., Viejo C., Ortega-Ruiz R. (2019). Well-Being and Romantic Relationships: A SystematicReview in Adolescence and Emerging Adulthood. International Journal of Environmental 
Research Public Health, 16, 2415. https://doi.org/10.3390/ijerp h16132415

Guerra-Bustamante, J., Leon-Del-Barco, B., Yuste-Tosina, R., LopezRamos, V. M., \& Mendo-Lazaro, S. (2019). Emotional intelligence and psychological well-being in adolescents. International Journal of Environmental Research and Public Health, 16(10). https://doi.org/10.3390/ijerph16101720

Gustems-Carnicer, J., \& Calderón, C. (2013). Coping strategies and psychological well-being among teacher education students. European Journal of Psychology of Education, 28(4), 1127-1140.

Hair Jr, J. F., Hult, G. T. M., Ringle, C., \& Sarstedt, M. (2017). A primer on partial least squares structural equation modeling (PLSSEM). Sage publications.

Harris, M. A. (2018). The relationship between physical inactivity and mental wellbeing: Findings from a gamification-based community-wide physical activity intervention. Health Psychol Open, 5(1), 2055102917753853. https://doi.org/10.1177/2055102917 753853

Hodzic, S., Scharfen, J., Ripoll, P., Holling, H., \& Zenasni, F. (2018). How efficient are emotional intelligence trainings: A meta-analysis. Emotion Review, 10(2), 138-148.

Hughes, M. C., Liu, Y., \& Baumbach, A. (2021). Impact of COVID-19 on the health and well-being of informal caregivers of people with dementia: A rapid systematic review. Gerontol Geriatr Med, 7, 23337214211020164. https://doi.org/10.1177/233372142110201 64

Josefsson, T., Lindwall, M., \& Archer, T. (2014). Physical exercise intervention in depressive disorders: meta-analysis and systematic review. Scandinavian Journal of Medicine \& Science in Sports, 24(2), 259-272. https://doi.org/10.1111/sms.12050

Juth, V., Dickerson, S. S., Zoccola, P. M., \& Lam, S. (2015). Understanding the utility of emotional approach coping: Evidence from a laboratory stressor and daily life. Anxiety, Stress, and Coping, 28(1), 50-70. https://doi.org/10.1080/10615806.2014.921912

Kilani, H., Alyaarubi, S., Zayed, K., Alzakwani, I., Bererhi, H., Shukri, R., \& Alrasadi, K. (2013). Physical fitness attributes, vitamin D, depression, and BMD in Omani's children. European Scientific Journal, 9(30).

Kilani, H. A., Bataineh, M. F., Al-Nawayseh, A., Atiyat, K., Obeid, O., Abu-Hilal, M. M., Mansi, T., Al-Kilani, M., Al-Kitani, M., El-Saleh, M., Jaber, R. M., Sweidan, A., Himsi, M., Yousef, I., Alzeer, F., Nasrallah, M., Al Dhaheri, A. S., Al-Za'abi, A., Allala, O., et al. (2020). Healthy lifestyle behaviors are major predictors of mental wellbeing during COVID-19 pandemic confinement: A study on adult Arabs in higher educational institutions. PLoS One, 15(12), e0243524. https://doi.org/10.1371/journal.pone.0243524

Kim, C. H., \& Kang, K.-A. (2019). The validity and reliability of the healthy lifestyle screening tool. Physical Therapy Rehabilitation Science, 8(2), 99-110.

Kotze, M., Visser, M., Makin, J., Sikkema, K., \& Forsyth, B. (2013). Psychosocial variables associated with coping of HIV-positive women diagnosed during pregnancy. AIDS and Behavior, 17(2), 498-507. https://doi.org/10.1007/s10461-012-0379-7

Lahoud, N., Zakhour, M., Haddad, C., Salameh, P., Akel, M., Fares, K., Hallit, S., \& Obeid, S. (2019). Burnout and its relationships with alexithymia, stress, self-esteem, depression, alcohol use disorders, and emotional intelligence: Results from a Lebanese cross-sectional study. The Journal of Nervous and Mental Disease, 207(8), 642-650. https://doi.org/10.1097/NMD.0000000000001017

Lane, A. M., Devonport, T. J., Soos, I., Karsai, I., Leibinger, E., \& Hamar, P. (2010). Emotional intelligence and emotions associated with optimal and dysfunctional athletic performance. Journal of sports science \& medicine, 9(3), 388.

Lane, A. M., \& Wilson, M. (2011). Emotions and trait emotional intelligence among ultra-endurance runners. Journal of Science and
Medicine in Sport, 14(4), 358-362. https://doi.org/10.1016/j. jsams.2011.03.001

Levinson, D., \& Christensen, K. (2003). Encyclopedia of community: From the village to the virtual world (Vol. 1). Sage.

Liu, Z., Doan, Q. V., Blumenthal, P., \& Dubois, R. W. (2007). A systematic review evaluating health-related quality of life, work impairment, and health-care costs and utilization in abnormal uterine bleeding. Value in Health, 10(3), 183-194.

Lukes, A. S., Baker, J., Eder, S., \& Adomako, T. L. (2012). Daily menstrual blood loss and quality of life in women with heavy menstrual bleeding. Womens Health (Lond), 8(5), 503-511. https:// doi.org/10.2217/whe.12.36

Luppa, M., Sikorski, C., Luck, T., Ehreke, L., Konnopka, A., Wiese, B., Weyerer, S., Konig, H. H., \& Riedel-Heller, S. G. (2012). Age- and gender-specific prevalence of depression in latest-life-systematic review and meta-analysis. Journal of Affective Disorders, 136(3), 212-221. https://doi.org/10.1016/j.jad.2010.11.033

Marquez-Arrico, J. E., Benaiges, I., \& Adan, A. (2015). Strategies to cope with treatment in substance use disorder male patients with and without schizophrenia. Psychiatry Research, 228(3), 752-759. https://doi.org/10.1016/j.psychres.2015.05.028

Martin-Maria, N., Caballero, F. F., Moreno-Agostino, D., Olaya, B., Haro, J. M., Ayuso-Mateos, J. L., \& Miret, M. (2020). Relationship between subjective well-being and healthy lifestyle behaviours in older adults: A longitudinal study. Aging \& Mental Health, 24(4), 611-619. https://doi.org/10.1080/13607863.2018. 1548567

Matud, M. P., Lopez-Curbelo, M., \& Fortes, D. (2019). Gender and psychological well-being. International Journal of Environmental Research and Public Health, 16(19). https://doi.org/10.3390/ijerp h16193531

Melki, I. S., Beydoun, H. A., Khogali, M., Tamim, H., Yunis, K. A., Neonatal, N. C. P., \& N. (2004). Household crowding index: A correlate of socioeconomic status and inter-pregnancy spacing in an urban setting. Journal of Epidemiology and Community Health, 58(6), 476-480. https://doi.org/10.1136/jech.2003.012690

Mertens, G., Gerritsen, L., Duijndam, S., Salemink, E., \& Engelhard, I. M. (2020). Fear of the coronavirus (COVID-19): Predictors in an online study conducted in march 2020. Journal of Anxiety Disorders, 74, 102258. https://doi.org/10.1016/j.janxdis.2020.102258

Mishra, P., Pandey, C. M., Singh, U., Gupta, A., Sahu, C., \& Keshri, A. (2019). Descriptive statistics and normality tests for statistical data. Annals of Cardiac Anaesthesia, 22(1), 67.

Moron, M., \& Biolik-Moron, M. (2021). Trait emotional intelligence and emotional experiences during the COVID-19 pandemic outbreak in Poland: A daily diary study. Personality and Individual Differences, 168, 110348. https://doi.org/10.1016/j.paid.2020. 110348

Obeid, S., Akel, M., Haddad, C., Fares, K., Sacre, H., Salameh, P., \& Hallit, S. (2019a). Factors associated with alexithymia among the Lebanese population: Results of a cross-sectional study. BMC Psychology, 7(1), 80. https://doi.org/10.1186/s40359-019-0353-5

Obeid, S., Haddad, C., Fares, K., Malaeb, D., Sacre, H., Akel, M., Salameh, P., \& Hallit, S. (2021). Correlates of emotional intelligence among Lebanese adults: The role of depression, anxiety, suicidal ideation, alcohol use disorder, alexithymia and work fatigue. $B M C$ Psychology, 9(1), 18. https://doi.org/10.1186/s40359-021-00525-6

Obeid, S., Haddad, C., Zakhour, M., Fares, K., Akel, M., Salameh, P., \& Hallit, S. (2019b). Correlates of self-esteem among the Lebanese population: A cross-sectional study. Psychiatria Danubina, 31(4), 429-439. https://doi.org/10.24869/psyd.2019.429

Obeid, S., Lahoud, N., Haddad, C., Sacre, H., Akel, M., Fares, K., Salameh, P., \& Hallit, S. (2020a). Factors associated with depression among the Lebanese population: Results of a cross-sectional 
study. Perspectives in Psychiatric Care, 56(4), 956-967. https:// doi.org/10.1111/ppc.12518

Obeid, S., Lahoud, N., Haddad, C., Sacre, H., Fares, K., Akel, M., Salameh, P., \& Hallit, S. (2020b). Factors associated with anxiety among the Lebanese population: The role of alexithymia, self-esteem, alcohol use disorders, emotional intelligence and stress and burnout. International Journal of Psychiatry in Clinical Practice, 24(2), 151-162. https://doi.org/10.1080/13651501. 2020.1723641

Pulido-Martos, M., Luque-Reca, O., Augusto-Landa, J. M., \& Ruiz, J. R. (2014). Emotional intelligence, personality and physical activity in institutionalized elders. Revista Argentina de Clinica Psicologica, 23(3), 231.

Rayan, A., \& Fawaz, M. (2018). Cultural misconceptions and public stigma against mental illness among Lebanese university students. Perspectives in Psychiatric Care, 54(2), 258-265. https://doi.org/ 10.1111/ppc.12232

Salameh, P., Hajj, A., Badro, D. A., Abou Selwan, C., Aoun, R., \& Sacre, H. (2020). Mental health outcomes of the COVID-19 pandemic and a collapsing economy: Perspectives from a developing country. Psychiatry Research, 294, 113520. https://doi.org/10. 1016/j.psychres.2020.113520

Salovey, P. E., \& Sluyter, D. J. (1997). Emotional development and emotional intelligence. Educational implications. Basic Books.

Sánchez-Álvarez, N., Extremera, N., \& Fernández-Berrocal, P. (2016). The relation between emotional intelligence and subjective wellbeing: A meta-analytic investigation. The Journal of Positive Psychology, 11(3), 276-285.

Satici, B., Saricali, M., Satici, S. A., \& Griffiths, M. D. (2020). Intolerance of uncertainty and mental wellbeing: Serial mediation by rumination and fear of COVID-19. International Journal of Mental Health and Addiction, 1-12. https://doi.org/10.1007/ s11469-020-00305-0

Schutte, N. S., Malouff, J. M., Simunek, M., McKenley, J., \& Hollander, S. (2002). Characteristic emotional intelligence and emotional well-being. Cognition \& Emotion, 16(6), 769-785.

Schutte, N. S., Malouff, J. M., Thorsteinsson, E. B., Bhullar, N., \& Rooke, S. E. (2007). A meta-analytic investigation of the relationship between emotional intelligence and health. Personality and Individual Differences, 42(6), 921-933.

Smith, J. A., Lumley, M. A., \& Longo, D. J. (2002). Contrasting emotional approach coping with passive coping for chronic myofascial pain. Annals of Behavioral Medicine, 24(4), 326-335.

Stanton, A. L., Kirk, S. B., Cameron, C. L., \& Danoff-Burg, S. (2000). Coping through emotional approach: Scale construction and validation. Journal of Personality and Social Psychology, 78(6), 1150.

Stoll, L. (2014). A short history of wellbeing research (pp. 1-19). A Complete Reference Guide.
Thomas, P. A., Liu, H., \& Umberson, D. (2017). Family relationships and well-being. Innovation in Aging, 1(3), igx025. https://doi.org/ 10.1093/geroni/igx025

Velten, J., Bieda, A., Scholten, S., Wannemuller, A., \& Margraf, J. (2018). Lifestyle choices and mental health: A longitudinal survey with German and Chinese students. BMC Public Health, 18(1), 632. https://doi.org/10.1186/s12889-018-5526-2

Villani, D., Sorgente, A., Iannello, P., \& Antonietti, A. (2019). The role of spirituality and religiosity in subjective well-being of individuals with different religious status. Frontiers in Psychology, 10, 1525. https://doi.org/10.3389/fpsyg.2019.01525

Warburton, D. E., \& Bredin, S. S. (2016). Reflections on physical activity and health: What should we recommend? The Canadian Journal of Cardiology, 32(4), 495-504. https://doi.org/10.1016/j. cjca.2016.01.024

Woon, L. S., Mansor, N. S., Mohamad, M. A., Teoh, S. H., Abdullah, L. B., \& M. F. I. (2021). Quality of life and its predictive factors among healthcare workers after the end of a movement lockdown: The salient roles of COVID-19 stressors, psychological experience, and social support. Frontiers in Psychology, 12, 652326. https://doi.org/10.3389/fpsyg.2021.652326

World Health Organization. (2004). The WHO cross-national study of health behavior in school-aged children from 35 countries: Findings from 2001-2002. The Journal of School Health, 74(6), 204-206. https://doi.org/10.1111/j.1746-1561.2004.tb07933.x

World Health Organization. (2020). WHO Director-General's opening remarks at the media briefing on COVID-19-11 March 2020. Available from: https://www.who.int/dg/speeches/detail/ who-director-general-s-opening-remarks-at-the-media-briefingon-covid-19\%2D\%2D-11-march-2020 [Accessed on March 20, 2021].

Xiong, J., Lipsitz, O., Nasri, F., Lui, L. M. W., Gill, H., Phan, L., Chen-Li, D., Iacobucci, M., Ho, R., Majeed, A., \& McIntyre, R. S. (2020). Impact of COVID-19 pandemic on mental health in the general population: A systematic review. Journal of Affective Disorders, 277, 55-64. https://doi.org/10.1016/j.jad.2020.08.001

Zayed, K., \& Kilani, H. (2014). Physical activity is associated with depression and self-esteem levels among Omani female children. Canadian Journal of Clinical Nutrition, 2(1), 5-18.

Publisher's Note Springer Nature remains neutral with regard to jurisdictional claims in published maps and institutional affiliations. 